\title{
Palladium-Catalyzed Nondirected Late-Stage C-H Deuteration of Arenes
}

\author{
Mirxan Farizyan, ${ }^{\dagger, \ddagger}$ Arup Mondal, ${ }^{+, \downarrow}$ Sourjya Mal, ${ }^{\dagger, \S}$ Fritz Deufel, ${ }^{\dagger, \S}$ and Manuel van Gemmeren ${ }^{*}$, \\ †Organisch-Chemisches Institut, Westfälische Wilhelms-Universität Münster, Corrensstraße 36, 48149 Münster, \\ Germany. \\ C-H activation, late-stage modification, deuteration, palladium, arenes
}

\begin{abstract}
We describe a palladium catalyzed non-directed late-stage deuteration of arenes. Key aspects include the use of $\mathrm{D}_{2} \mathrm{O}$ as a convenient and easily available deuterium source and the discovery of highly active $N, N$-bidentate ligands containing an $\mathrm{N}$-acyl sulfonamide group. The reported protocol enables high degrees of deuterium incorporation via a reversible $\mathrm{C}-\mathrm{H}$ activation step and features an extraordinary functional group tolerance, allowing for the deuteration of complex substrates. This is exemplified by the late-stage isotopic labelling of various pharmaceutically relevant motifs and related scaffolds. We expect that this method, amongst other applications, will prove useful as a tool in drug development processes and for mechanistic studies.
\end{abstract}

Over the last decades the incorporation of hydrogen atom isotopes into organic molecules has received considerable attention and remains a key research goal in both academic and industrial research. ${ }^{1}$ Isotopically labelled compounds feature a broad range of applications, starting from their use in the elucidation of reaction mechanisms ${ }^{2}$ or as internal standards in mass-spectrometry studies. ${ }^{3}$ Isotopically labelled analogs of bioactive molecules play a critical role in the drug discovery processes, for example in absorption, distribution, metabolism, and excretion (ADME) studies to gain knowledge of their metabolic profile and toxicity. ${ }^{4}$ In an increasing number of cases deuterated molecules are marketed as new pharmaceuticals ${ }^{5}$ often characterized by improved pharmacokinetic and pharmacodynamic properties. These diverse applications have spurred a continued interest in the development of convenient and robust synthetic methods to incorporate deuterium into complex aromatic scaffolds, which occur in many bioactive molecules and related compounds. ${ }^{1 \mathrm{~d}, \mathrm{e}}$

Methods such as the de novo synthesis of complex deuterated analogs or the introduction of $\mathrm{D} / \mathrm{T}$ in prefunctionalized positions often prove to be time consuming and cost-intensive. ${ }^{6}$ Efforts have thus been made to establish methods for the direct hydrogen isotope exchange (HIE) of aromatic $\mathrm{C}-\mathrm{H}$ bonds, that could in principle enable an efficient post-synthetic incorporation of hydrogen isotopes into bioactive molecules. ${ }^{1 \mathrm{~d}, \mathrm{e}, 7}$

Traditional methods for the direct H/D-exchange of arenes include pH-dependent methods (Scheme 1A), where the incorporation of deuterium is achieved by the use of Brønsted/Lewis-acids mostly via an $\mathrm{S}_{\mathrm{E}} \mathrm{Ar}$-type mechanism. ${ }^{8}$ Examples of base-mediated HIE reactions of arenes are also known. ${ }^{9}$ Owing to the typically harsh reaction conditions these methods are usually employed for simple arenes. Heterogenous methods for the HIE of arenes are well developed and high activity could be achieved with many transition metals. ${ }^{3 e, 10}$ This approach offers technical advantages like simple purification, ${ }^{11}$ but faces challenges such as undesired side reactions. ${ }^{12}$

\section{Scheme 1. Approaches towards the Deuteration of} Arenes

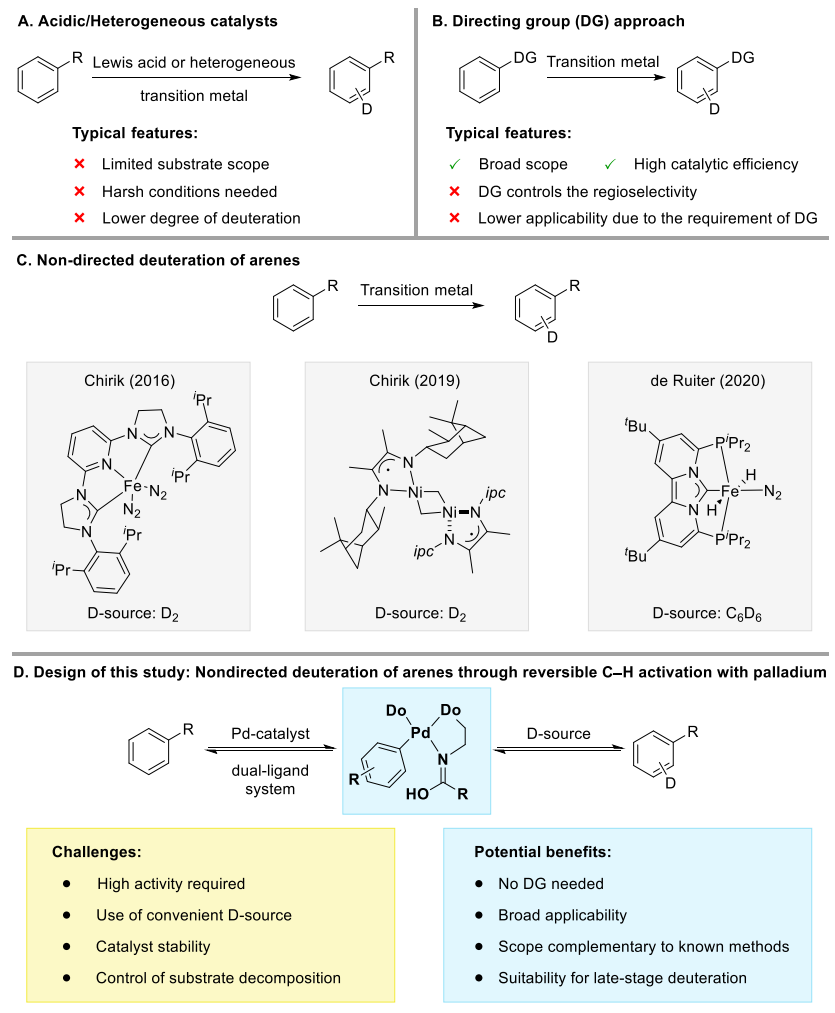


The potential to achieve high selectivities for the HIE under comparably mild conditions and thus enabling a broader functional group tolerance, has spurred research towards homogeneously catalyzed methods.1b,1d,1e,13 In this context, the use of directing groups (DGs) has proven highly useful. ${ }^{14}$ Methods based on various transition metals have been established and feature high efficiencies and broad functional group tolerances (Scheme 1B). ${ }^{15}$ While DGs usually lead to a selective deuteration in the ortho position, specialized DGs to achieve meta deuteration have also been described. ${ }^{16}$

Recent studies have focused on the use of native functional groups rather than designed DG to enable directed latestage $\mathrm{C}-\mathrm{H}$ deuteration. ${ }^{17}$

These directed protocols are complemented by nondirected approaches, ${ }^{18}$ which offer the potential to address unbiased $\mathrm{C}-\mathrm{H}$ bonds without requiring a DG on the substrate, thus potentially enabling the H/D exchange on a substantially broader range of substrates. Non-directed methods for the deuteration of simple arenes are well established, ${ }^{19}$ but catalysts that enable the non-directed HIE of drug molecules and other similarly complex scaffolds have only recently been described (Scheme 1C). ${ }^{20}$ Chirik and co-workers introduced an iron catalyst capable of inducing HIE with a variety of pharmaceuticals using $\mathrm{D}_{2}$ as deuterium source.20a The same group later described a Nibased catalyst, which delivered deuterated and tritiated drug molecules efficiently using $\mathrm{D}_{2}$ and $\mathrm{T}_{2}$ as deuterium source. $^{20 c}$ Recently, de Ruiter et al. described a Fe-PCPpincer complex that proves highly active for the nondirected H/D-exchange of arenes using $\mathrm{C}_{6} \mathrm{D}_{6}$ as deuterium source and tolerates a considerable range of functional groups. 20 e These catalysts provided substantial progress towards the mild and efficient HIE of complex molecules and raised interest in the development of complementary methods. ${ }^{1 e, 20 \mathrm{f}}$

Our group has recently developed Pd-catalysts for the nondirected late-stage functionalization of complex (hetero)arenes. ${ }^{21,22}$ An extensive mechanistic investigation of our dual ligand-based catalyst system ${ }^{23}$ showed that the $\mathrm{C}-\mathrm{H}$ activation step is reversible (Scheme 1D). We envisioned that a highly active catalyst for the reversible $\mathrm{C}-\mathrm{H}$ activation of arenes using our dual ligand design could enable a homogenous non-directed method for the Pdcatalyzed late-stage HIE with the potential to complement existing methods based on 3d-metals with regard to the substrate scope and/or deuterium source used.

Based on these considerations, we engaged in detailed optimization studies. ${ }^{24}$ Table 1 shows the deuteration of model substrate $\mathbf{1}$ using different bidentate ligands in $\mathrm{d}_{1}$ HFIP. Acetyl glycine (L1) as ligand resulted in a moderate H/D-exchange (Entry 1). Building upon our recent finding that bulky aryl amides as CMD promoting group in ethylenediamine ligands show superior activity in $\mathrm{HIE},{ }^{24}$ we synthesized the analogous glycine derivates $\mathbf{L 2}$ and L3 (Entries 2 and 3). These $\alpha$-amino acid derived ligands lead to a significant improvement in deuterium incorporation. An extensive search for novel ligand classes with improved properties regarding activity and regioselectivity led us to discover $N, N$-bidentate ligands which feature $N$-acyl sulfonamide groups. Interestingly, introducing this motif instead of the carboxylic acid moiety offers additional potential for ligand diversification by introducing further variable positions. Using mesityl-substituted ligand $\mathbf{L} \mathbf{4}$ gave similar results as acetyl glycine, albeit with less deuteration in the ortho-position, whereas $\mathbf{L 5}$ lead to decreased values (Entries 4 and 5). A significant improvement resulted when the two structural variations were combined in $\mathbf{L 6}$ and $\mathbf{L 7}$ (Entries 6 and 7).

Table 1. Optimization of the Ligand Structure.a, $b$

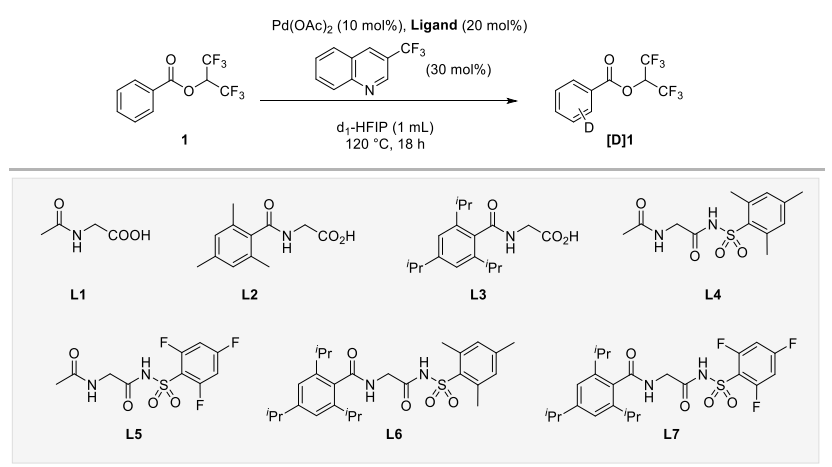

\begin{tabular}{|c|c|c|c|c|c|c|}
\hline \multirow{2}{*}{ Entry } & \multirow{2}{*}{ Ligand } & \multirow{2}{*}{$\begin{array}{c}\text { Yield } \\
(\%)\end{array}$} & \multicolumn{3}{|c|}{ D-content (\%, NMR) } & \multirow{2}{*}{$\begin{array}{c}\text { Total D- } \\
\text { content } \\
\text { (MS) }\end{array}$} \\
\hline & & & Ortho & Meta & Para & \\
\hline 1 & L1 & 99 & 11 & 50 & 23 & 1.66 \\
\hline 2 & L2 & 95 & 22 & 73 & 41 & 2.42 \\
\hline 3 & L3 & 97 & 24.5 & 79 & 47 & 2.65 \\
\hline 4 & L4 & 98 & 4 & 46 & 23 & 1.27 \\
\hline 5 & L5 & 98 & 7 & 35 & 21 & 1.05 \\
\hline 6 & L6 & 97 & 5 & 72 & 46 & 2.08 \\
\hline 7 & L7 & 97 & 17 & 90 & 74 & 2.87 \\
\hline $8^{c}$ & L7 & 95 & 39 & 95 & 84 & 3.51 \\
\hline $9 \mathrm{c,d}$ & L7 & 99 & 34 & 60 & 32 & 2.15 \\
\hline $10^{c}$ & No L7 & 98 & 0 & 0 & 0 & 0 \\
\hline $11^{\mathrm{c}, \mathrm{e}}$ & L7 & 94 & 62 & 95 & 95 & 4.05 \\
\hline
\end{tabular}

${ }^{a}$ Reactions were performed on a $0.1 \mathrm{mmol}$ scale. ${ }^{b}$ Yields and degrees of deuteration were determined by ${ }^{1} \mathrm{H}-\mathrm{NMR}$ spectroscopy using mesitylene as internal standard. The total deuterium content was determined by mass spectrometry. ${ }^{c}$ Reaction performed with $\mathrm{D}_{2} \mathrm{O}$ :HFIP (7:3) as solvent. Note: since $\mathrm{D}_{2} \mathrm{O}$ is used as part of the solvent system, this corresponds to an excess of approx. 390 equivalents. ${ }^{d}$ No 3-trifluoromethyl quinoline. ${ }^{e}$ Reaction performed with $48 \mathrm{~h}$ reaction time.

An investigation of alternative, more convenient deuterium sources showed that improved results are obtained with a mixture of $\mathrm{D}_{2} \mathrm{O}$ :HFIP (7:3) as solvent (Entry 8). This is particularly attractive since $\mathrm{d}_{1}$-HFIP, which is comparably costly or needs to be synthesized, can be replaced by a cheap and convenient deuterium source. Control experiments at this stage revealed that both ligands are indeed required to obtain optimal results (Entries 9 and 10). Finally, nearly complete deuteration of the meta and para positions was observed when using L7 with an increased reaction time (Entry 11). 


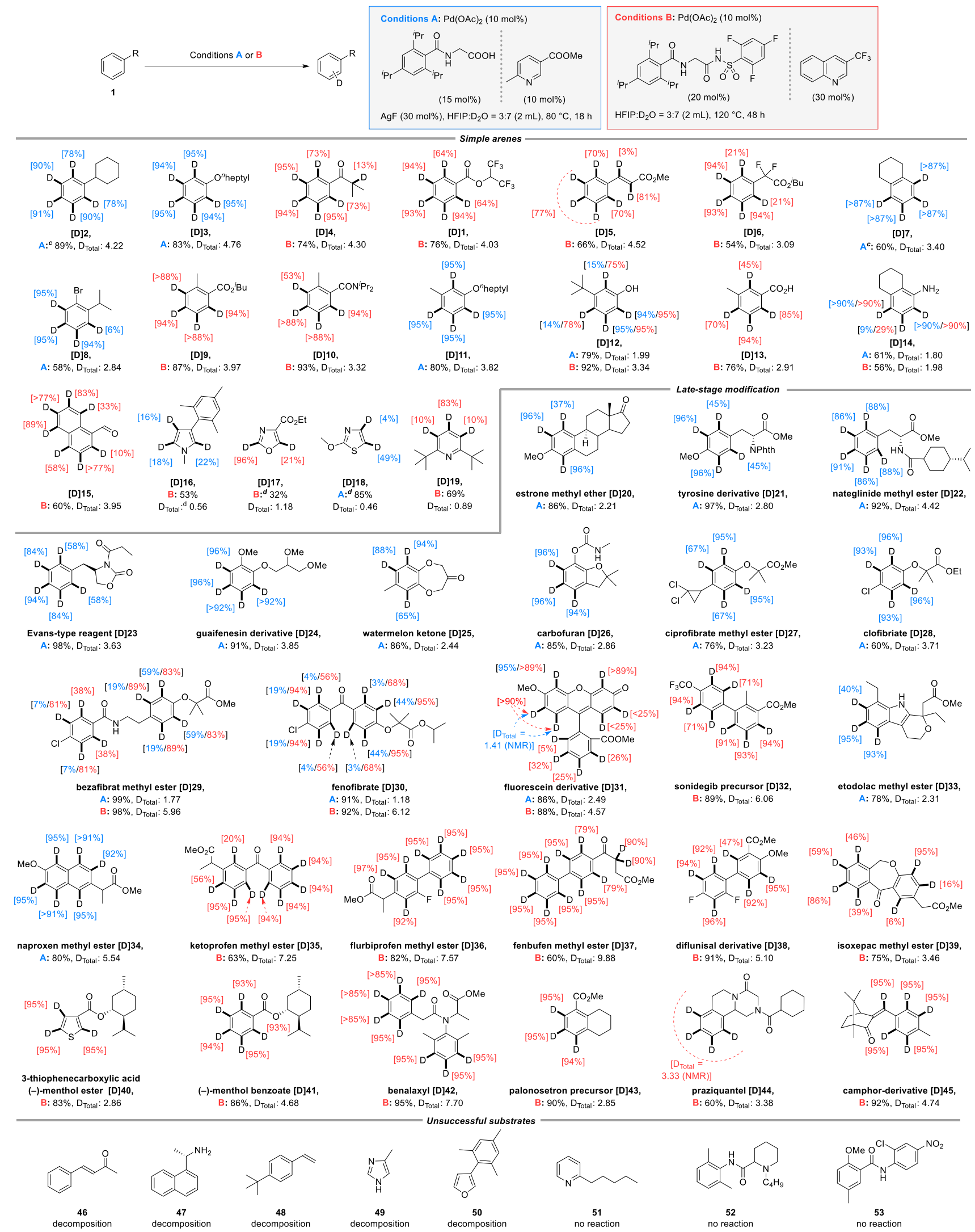

${ }^{a}$ Reactions were performed on a $0.2 \mathrm{mmol}$ scale. ${ }^{b}$ Positions with less than $10 \% \mathrm{D}$ incorporation are typically not depicted explicitly but reflected in the $\mathrm{D}_{\text {Total }}$ value (For experimental details: see the SI). ${ }^{c}$ Reaction performed at $40{ }^{\circ} \mathrm{C}$ for $72 \mathrm{~h} .{ }^{\text {d }}$ Determined by ${ }^{1} \mathrm{H}-\mathrm{NMR}$ spectroscopy. 
Interestingly, the seemingly sterically most hindered ligand enables the highest deuteration in the ortho-position. This can be explained by two factors. Firstly, the steric bulk does not point towards the substrate in the key $\mathrm{C}-\mathrm{H}$ activation step, ${ }^{23}$ and secondly, the ligand enables the highest overall activities, such that even the least reactive site on the substrate is deuterated, although still substantially slower than the other positions (Entries 8 and 11). Since the conditions developed in Table 1 (Conditions B in Scheme 2) were found using a particularly challenging electron-poor substrate, we hypothesized that more electron-rich substrates might be deuterated under milder conditions. A re-optimization (see the SI for details) delivered a second set of reaction conditions using $\mathbf{L} 3$ and $\mathrm{AgF}$ as an additive at lower temperatures (Conditions A in Scheme 2)

Having established two sets of conditions we evaluated the scope (Scheme 2). We initiated our investigation by using simple arenes to assess the general functional group tolerance when applying our catalyst systems. The yields of the re-isolated substrates were in general good to excellent. The use of alkylated arene $\mathbf{2}$ under very mild conditions resulted in high H/D-exchange in the arene moiety $\left(D_{\text {Total }}=4.22\right)$. Excellent degrees of deuteration were also observed for the anisole derivative 3 . Notably, our protocol tolerates ketones (4), a functional group that is challenging for many literature methods. This observation is of particular importance due to the presence of this functionality in a wide range of bioactive molecules. Using Conditions $\mathrm{B}$, in addition to the deuteration on the arene core, butyrophenone $\mathbf{4}$ underwent little but measurable isotope exchange in the relatively acidic $\alpha$-position, presumably via an acid-base mechanism. The electron-poor arenes 1, 5, and $\mathbf{6}$ were likewise subjected to Conditions B, leading to very high degrees of deuteration, especially in the meta and para positions. Di-alkyl substituted substrate 7 smoothly underwent H/D exchange in the arene moiety. Interestingly, halogenated arene $\mathbf{8}$ was well tolerated under Conditions A giving the re-isolated substrate in good yield and with a high overall degree of deuteration. Further disubstituted arenes containing ester-, amide-, ether-, and free hydroxy groups (9-12) gave high levels of deuterium incorporation (up to $\mathrm{D}_{\text {Total }}=3.97$ ). Aniline-derivatives (14), aldehydes and extended p-systems (15) are likewise tolerated under the reaction conditions. Finally, we probed whether our protocol can be used for heterocycles. The comparably electron-rich heteroarenes pyrrole 16, oxazole $\mathbf{1 7}$, and thiazole 18 could be deuterated in moderate to good yields and with appreciable levels of deuterium incorporation. The deuteration of pyridine-derivative 19 confirmed that this substrate class is in principle amenable if the $\mathrm{N}$-atom is sufficiently shielded to avoid catalyst poisoning.

We proceeded to evaluate the suitability of our method for the late-stage deuteration of bioactive molecules and related scaffolds. Subjecting estrone derivative $\mathbf{2 0}$ to Conditions A delivered the deuterated compound [D]20 in very good yield and a high degree of deuteration on the arene moiety. Interestingly, the sterically most congested position underwent $H / D$-exchange to a reduced extent. Similarly, with tyrosine derivative $\mathbf{2 1}$ the deuterium incorporation into the sterically more hindered position was lower than ortho to the methoxy-group. Furthermore, nateglinide methyl ester 22, the Evans-type reagent 23, guaifenesin derivative 24, watermelon ketone (25), and carbofuran (26) were subjected to Conditions A, leading to almost complete deuterium incorporation into the respective arene moieties, thereby demonstrating a functional group tolerance towards amides, esters, ethers, and carbamates.

Representatives of the fibrate class such as cipofibrate methyl ester (27), clofibrate (28), benzafibrate methyl ester (29), and fenofibrate (30) were efficiently deuterated. Due to the presence of an electron-poor and a rather electron-rich arene moiety, substrates 29 and $\mathbf{3 0}$ were subjected to both Conditions A and B. With the milder reaction Conditions $A$, a good degree of deuteration on the electron-rich arene was observed, while with Conditions B both arene moieties were efficiently deuterated.

The fluorescein-derivative $\mathbf{3 1}$ was also subjected to both catalyst systems. With Conditions A, the electron-rich positions underwent efficient H/D-exchange $\left(D_{\text {Total }}=2.49\right)$ exclusively, whereas Conditions B lead to a substantially increased overall deuterium incorporation $\left(\mathrm{D}_{\text {Total }}=4.57\right)$. Nearly complete deuteration of the arene moieties occurred using the sonidegib precursor 32. The etodolac methyl ester (33), which contains an indole substructure, likewise underwent an efficient H/D-exchange using Conditions A.

Methyl ester derivatives of naproxen (34), ketoprofen (35), and flurbiprofen (36), as representatives of the profen class of medications were almost completely deuterated at the arene position (up to $\mathrm{D}_{\text {Total }}=7.57$ ). The fenbufen derivative 37 could likewise be deuterated. It should be noted that besides the aromatic core, the $\alpha$-keto position underwent almost complete deuteration presumably due to an acid/base-type mechanism.

Derivatives of diflunisal (38) and isoxepac (39) gave high degrees of deuteration using Conditions B. (-)-Menthol esters of 3-thiophenecarboxylic acid (40) and benzoic acid (41) could both be deuterated efficiently. Finally, subjecting benalaxyl (42), the palonosetron precursor 43, praziquantel (44), and camphor-derivative 45 to our catalyst led to nearly complete deuterium incorporation in the arene moieties, as well as the olefinic position of $\mathbf{4 5}$.

Finally, Scheme 2 depicts a number of substrates that could not be deuterated using our method either due to substrate decomposition (46-50) or due to an absence of reactivity that presumably originates from catalyst poisoning by the substrate or its insolubility in the reaction medium (51-53).

As evidenced by the above scope studies, we have developed a broadly applicable protocol for the nondirected late-stage deuteration of arenes using dual ligandbased palladium catalysts. Enabled by the development of a novel ligand class, a wide variety of bioactive molecules and related structures could be isotopically labelled using $\mathrm{D}_{2} \mathrm{O}$ as a cheap and convenient deuterium source. This method is applicable to both electron-rich and electron-poor arenes and tolerates a wide range of functional groups, rendering it complementary to established protocols. We expect that our catalysts will prove useful for isotopic labelling in a variety of fields, with potential applications ranging from mechanistic studies to drug development. 


\section{ASSOCIATED CONTENT}

Supporting Information. The Supporting Information is available free of charge via the Internet at http://pubs.acs.org. Optimization of reaction conditions, preparative procedures, analytical data for the compounds are described.

\section{Corresponding Author}

*mvangemmeren@uni-muenster.de

\section{Author Contributions}

$\ddagger$ M.F., and A.M. contributed equally to this work. § S.M. and F.D. contributed equally to this work.

\section{Funding Sources}

We acknowledge generous financial support by the DFG (Emmy Noether Programme) and the WWU Münster. Additionally, this project has received funding from the European Research Council (ERC) under the European Union's Horizon 2020 research and innovation programme (grant agreement No 946044).

\section{Notes}

The authors declare no competing financial interest.

\section{ACKNOWLEDGMENT}

We thank all members of our MS and NMR department for their excellent service. We thank A. Uttry for helpful scientific discussions. Furthermore, we thank Prof. Dr. Frank Glorius for his generous support.

\section{ABBREVIATIONS}

HFIP, 1,1,1,3,3,3-hexafluoropropan-2-ol.

\section{REFERENCES}

(1) (a) Junk, T.; Catallo, W. J. Hydrogen isotope exchange reactions involving C-H (D, T) bonds Chem. Soc. Rev. 1997, 26, 401406. (b) Atzrodt, J.; Derdau, V.; Fey, T.; Zimmermann, J. The renaissance of H/D exchange Angew. Chem., Int. Ed. 2007, 46, 7744-7765. (c) Atzrodt, J.; Derdau, V.; Kerr, W. J.; Reid, M. Deuterium- and Tritium-Labelled Compounds: Applications in the Life Sciences Angew. Chem., Int. Ed. 2018, 57, 1758-1784. (d) Atzrodt, J.; Derdau, V.; Kerr, W. J.; Reid, M. C-H Functionalisation for Hydrogen Isotope Exchange Angew. Chem., Int. Ed. 2018, 57, 30223047. (e) Kang, Q.-K.; Shi, H. Catalytic Hydrogen Isotope Exchange Reactions in Late-Stage Functionalization Synlett 2021. DOI: 10.1055/a-1354-0367

(2) Simmons, E. M.; Hartwig, J. F. On the interpretation of deuterium kinetic isotope effects in $\mathrm{C}-\mathrm{H}$ bond functionalizations by transition-metal complexes Angew. Chem., Int. Ed. 2012, 51, 3066-3072.

(3) (a) Wehmeyer, K. R.; Knight, P. M.; Parry, R. C. Evaluation of a benchtop ion trap gas chromatographic-tandem mass spectrometric instrument for the analysis of a model drug, tebufelone, in plasma using a stable-isotope internal standard $J$. Chromatogr. B 1996, 676, 53-59. (b) Kao, C.-Y.; Giese, R. W. Measurement of N7-(2'-hydroxyethyl)guanine in human DNA by gas chromatography electron capture mass spectrometry Chem. Res. Toxicol. 2005, 18, 70-75. (c) Stokvis, E.; Rosing, H.; Beijnen, J. $\mathrm{H}$. Stable isotopically labeled internal standards in quantitative bioanalysis using liquid chromatography/mass spectrometry: necessity or not? Rapid Commun. Mass Spectrom. 2005, 19, 401407. (d) Mutlib, A. E. Application of stable isotope-labeled compounds in metabolism and in metabolism-mediated toxicity studies Chem. Res. Toxicol. 2008, 21, 1672-1689. (e) Atzrodt, J.; Derdau, V. Pd- and Pt-catalyzed H/D exchange methods and their application for internal MS standard preparation from a Sanofi-
Aventis perspective J. Chem. Soc., Perkin Trans. 2 2010, 53, 674685.

(4) (a) Marathe, P. H.; Shyu, W. C.; Humphreys, W. G. The use of radiolabeled compounds for ADME studies in discovery and exploratory development Curr. Pharm. Des. 2004, 10, 2991-3008. (b) Harbeson, S. L.; Tung, R. D. Deuterium in Drug Discovery and Development. In; Annual Reports in Medicinal Chemistry; Elsevier, 2011; pp 403-417. (c) Isin, E. M.; Elmore, C. S.; Nilsson, G. N.; Thompson, R. A.; Weidolf, L. Use of radiolabeled compounds in drug metabolism and pharmacokinetic studies Chem. Res. Toxicol. 2012, 25, 532-542. (d) Gant, T. G. Using deuterium in drug discovery: leaving the label in the drug J. Med. Chem. 2014, 57, 3595-3611. (e) Elmore, C. S.; Bragg, R. A. Isotope chemistry; a useful tool in the drug discovery arsenal Bioorganic Med. Chem. Lett. 2015, 25, 167-171.

(5) (a) Mullard, A. FDA approves first deuterated drug Nat. Rev. Drug. Discov. 2017, 16, 305. (b) Pirali, T.; Serafini, M.; Cargnin, S.; Genazzani, A. A. Applications of Deuterium in Medicinal Chemistry J. Med. Chem. 2019, 62, 5276-5297.

(6) (a) Thomas, A. F. Deuterium labeling in organic chemistry; Appleton-Century-Crofts, 1971. (b) Chapelle, M. R.; Kent, B. B.; Jones, J. R.; Lu, S.-Y.; Morgan, A. D. Development of combined microwave-enhanced labelling procedures for maximising deuterium incorporation Tetrahedron Lett. 2002, 43, 5117-5118. (c) Alonso, F.; Beletskaya, I. P.; Yus, M. Metal-mediated reductive hydrodehalogenation of organic halides Chem. Rev. 2002, 102, 4009-4091. (d) Guaragna, A.; Pedatella, S.; Pinto, V.; Palumbo, G. Synthesis of C-Protected 2,2-Dideutero $\beta 3$-Amino Acids Synthesis 2006, 2006, 4013-4016. (e) Fontana, E.; Venegoni, S. Syntheses of $(R, S)$-naproxen and its 6-0-desmethylated metabolite labelled with 2H J. Chem. Soc., Perkin Trans. 2 2008, 51, 239-241. (f) Kallepalli, V. A.; Gore, K. A.; Shi, F.; Sanchez, L.; Chotana, G. A.; Miller, S. L.; Maleczka, R. E.; Smith, M. R. Harnessing C-H Borylation/Deborylation for Selective Deuteration, Synthesis of Boronate Esters, and Late Stage Functionalization J. Org. Chem. 2015, 80, 8341-8353. (g) Upshur, M. A.; Chase, H. M.; Strick, B. F.; Ebben, C. J.; Fu, L.; Wang, H.; Thomson, R. J.; Geiger, F. M. Vibrational Mode Assignment of $\alpha$-Pinene by Isotope Editing: One Down, Seventy-One To Go J. Phys. Chem. A 2016, 120, 2684-2690. (h) Neumann, K. T.; Lindhardt, A. T.; Bang-Andersen, B.; Skrydstrup, T. Synthesis and selective $2 \mathrm{H}-, 13 \mathrm{C}-$, and $15 \mathrm{~N}$-labeling of the Tau protein binder THK-523 J. Labelled Compd. Radiopharm. 2017, 60, 30-35.

(7) Voges, R.; Heys, J. R.; Moenius, T. Preparation of compounds labeled with tritium and carbon-14; Wiley, 2009.

(8) (a) Garnett, J. L.; Long, M. A.; Vining, R. F. W.; Mole, T. New simple method for rapid, selective aromatic deuteration using organoaluminum dihalide catalysts J. Am. Chem. Soc. 1972, 94, 5913-5914. (b) Long, M. A.; Garnett, J. L.; Vining, R. F. W. Rapid deuteriation and tritiation of organic compounds using organometallic and elemental halides as catalysts J. Chem. Soc., Perkin Trans. 2 1975, 1298. (c) Seibles, J. C.; Bollinger, D. M.; Orchin, M. Synthesis of Perdeuteriobenzo[a] pyrene Angew. Chem., Int. Ed. 1977, 16, 656-657. (d) Branch, C. S.; Barron, A. R. Arene-mercury complexes stabilized by gallium chloride: relative rates of H/D and arene exchange J. Am. Chem. Soc. 2002, 124, 14156-14161. (e) Hakala, U.; Wähälä, K. Expedient deuterolabeling of polyphenols in ionic liquids- $\mathrm{DCl} / \mathrm{D}_{2} \mathrm{O}$ under microwave irradiation J. Org. Chem. 2007, 72, 5817-5819. (f) Martins, A.; Lautens, M. A simple, costeffective method for the regioselective deuteration of anilines $\mathrm{Org}$. Lett. 2008, 10, 4351-4353. (g) Mačková, M.; Himl, M.; Minářová, L.; Lang, J.; Lhoták, P. Regioselective deuteration of 25,27dialkoxycalix [4] arenes Tetrahedron Lett. 2011, 52, 2543-2546. (h) Zhou, L.; Bian, X.; Yang, S.; Mu, B. A two-step synthesis of deuterium labeled 8, 8, 9, 9-d4-hexadecane from nonanoic acid J. Chem. Soc., Perkin Trans. 2 2012, 55, 158-160. (i) Murai, Y.; Wang, L.; Masuda, K.; Sakihama, Y.; Hashidoko, Y.; Hatanaka, Y.; Hashimoto, M. Rapid and Controllable Hydrogen/Deuterium Exchange on Aromatic Rings of $\alpha$-Amino Acids and Peptides Eur. J. Org. Chem. 2013, 2013, 
5111-5116. (j) Müller, K.; Seubert, A. Synthesis of deuteriumlabelled fluorobenzoic acids to be used as internal standards in isotope dilution mass spectrometry Isotopes Environ Health Stud 2014, 50, 88-93. (k) Wang, L.; Murai, Y.; Yoshida, T.; Okamoto, M.; Masuda, K.; Sakihama, Y.; Hashidoko, Y.; Hatanaka, Y.; Hashimoto, M. Hydrogen/deuterium exchange of cross-linkable $\alpha$-amino acid derivatives in deuterated triflic acid Biosci. Biotechnol. Biochem. 2014, 78, 1129-1134. (l) Munz, D.; Webster-Gardiner, M.; Fu, R.; Strassner, T.; Goddard, W. A.; Gunnoe, T. B. Proton or Metal? The H/D Exchange of Arenes in Acidic Solvents ACS Catal. 2015, 5, 769775. (m) Fischer, O.; Hubert, A.; Heinrich, M. R. Shifted Selectivity in Protonation Enables the Mild Deuteration of Arenes Through Catalytic Amounts of Bronsted Acids in Deuterated Methanol J. Org. Chem. 2020, 85, 11856-11866.

(9) (a) Beak, P.; Brown, R. A. The tertiary amide as an effective director of ortho lithiation J. Org. Chem. 1982, 47, 34-46. (b) Clayden, J.; Pink, J. H.; Westlund, N.; Wilson, F. X. Controlling the regioselectivity of lithiation using kinetic isotope effects: Deuterium as a protecting group for carbon Tetrahedron Lett. 1998, 39, 8377-8380. (c) Ahmed, A.; Clayden, J.; Rowley, M. Anion translocation in organolithiums: A mechanism for the lithiation and cyclisation of tertiary naphthamides Tetrahedron Lett. 1998, 39, 6103-6106. (d) Zhan, M.; Xu, R.; Tian, Y.; Jiang, H.; Zhao, L.; Xie, Y.; Chen, Y. A Simple and Cost-Effective Method for the Regioselective Deuteration of Phenols Eur. J. Org. Chem. 2015, 2015, 3370-3373. (e) Salamanca, V.; Albéniz, A. C. Deuterium Exchange between Arenes and Deuterated Solvents in the Absence of a Transition Metal: Synthesis of D-Labeled Fluoroarenes Eur. J. Org. Chem. 2020, 2020, 3206-3212.

(10) (a) Fraser, R. R.; Renaud, R. N. The Steric Effect in the Platinum-Catalyzed Exchange Reaction between Aromatic Ring Protons and Deuterium Oxide J. Am. Chem. Soc. 1966, 88, 43654370. (b) Matsubara, S.; Yokota, Y.; Oshima, K. Palladium-catalyzed decarboxylation and decarbonylation under hydrothermal conditions: decarboxylative deuteration $\mathrm{Org}$. Lett. 2004, 6, 20712073. (c) Yamamoto, M.; Yokota, Y.; Oshima, K.; Matsubara, S. H-D exchange reaction on benzene ring of polystyrene in hydrothermal deuterium oxide with platinum(IV) oxide catalyst Chem. Commun. 2004, 1714-1715. (d) Yamamoto, M.; Oshima, K.; Matsubara, S. Platinum(IV) oxide catalyzed $\mathrm{H}-\mathrm{D}$ exchange reactions in arylsilanes Org. Lett. 2004, 6, 5015-5017. (e) Derdau, V.; Atzrodt, J.; Zimmermann, J.; Kroll, C.; Brückner, F. Hydrogen-deuterium exchange reactions of aromatic compounds and heterocycles by NaBD4-activated rhodium, platinum and palladium catalysts Chem. Eur. J. 2009, 15, 10397-10404. (f) Sajiki, H. Development of deuterium labeling method based on the heterogeneous platinum group metal-catalyzed C-H activation J. Phys. Soc. Japan 2013, 133 1177-1193. (g) Pieters, G.; Taglang, C.; Bonnefille, E.; Gutmann, T.; Puente, C.; Berthet, J.-C.; Dugave, C.; Chaudret, B.; Rousseau, B. Regioselective and stereospecific deuteration of bioactive aza compounds by the use of ruthenium nanoparticles Angew. Chem., Int. Ed. 2014, 53, 230-234. (h) Bresó-Femenia, E.; Godard, C.; Claver, C.; Chaudret, B.; Castillón, S. Selective catalytic deuteration of phosphorus ligands using ruthenium nanoparticles: a new approach to gain information on ligand coordination Chem. Commun. 2015, 51, 16342-16345. (i) Sawama, Y.; Nakano, A.; Matsuda, T.; Kawajiri, T.; Yamada, T.; Sajiki, H. H-D Exchange Deuteration of Arenes at Room Temperature Org. Process Res. Dev. 2019, 23, 648-653. (j) Park, K.; Ito, N.; Yamada, T.; Sajiki, H. Efficient Continuous-Flow H-D Exchange Reaction of Aromatic Nuclei in $\mathrm{D}_{2} \mathrm{O} / 2$-PrOH Mixed Solvent in a Catalyst Cartridge Packed with Platinum on Carbon Beads Bull. Chem. Soc. Jpn 2021, 94, 600605.

(11) Smith, G. V.; Notheisz, F. Heterogeneous catalysis in organic chemistry; Academic Press, 1999.

(12) Beller, M.; Bolm, C. Transition metals for organic synthesis:Building blocks and fine chemicals, $2^{\text {nd }}$, rev. and enl. ed.; Wiley-VCH, 2004.
(13) (a) Feng, Y.; Lail, M.; Foley, N. A.; Gunnoe, T. B.; Barakat, K. A.; Cundari, T. R.; Petersen, J. L. Hydrogen-deuterium exchange between $\mathrm{TpRu}\left(\mathrm{PMe}_{3}\right)(\mathrm{L}) \mathrm{X}\left(\mathrm{L}=\mathrm{PMe}_{3}\right.$ and $\mathrm{X}=\mathrm{OH}, \mathrm{OPh}, \mathrm{Me}, \mathrm{Ph}$, or $\mathrm{NHPh} ; \mathrm{L}=\mathrm{NCMe}$ and $\mathrm{X}=\mathrm{Ph}$ ) and deuterated arene solvents: evidence for metal-mediated processes J. Am. Chem. Soc. 2006, 128, 7982-7994. (b) Allen, P. H.; Hickey, M. J.; Kingston, L. P.; Wilkinson, D. J. Metal-catalysed isotopic exchange labelling: 30 years of experience in pharmaceutical R\&D J. Chem. Soc., Perkin Trans. 2 2010, 53, 731-738. (c) Lockley, W. J. S.; Heys, J. R. Metal-catalysed hydrogen isotope exchange labelling: a brief overview J. Chem. Soc., Perkin Trans. 2 2010, 53, 635-644. (d) Di Giuseppe, A.; Castarlenas, R.; Oro, L. A. Mechanistic considerations on catalytic H/D exchange mediated by organometallic transition metal complexes C. R. Chim 2015, 18, 713-741.

(14) (a) Whisler, M. C.; MacNeil, S.; Snieckus, V.; Beak, P. Beyond thermodynamic acidity: a perspective on the complex-induced proximity effect (CIPE) in deprotonation reactions Angew. Chem., Int. Ed. 2004, 43, 2206-2225. (b) Sambiagio, C.; Schönbauer, D.; Blieck, R.; Dao-Huy, T.; Pototschnig, G.; Schaaf, P.; Wiesinger, T.; Zia, M. F.; Wencel-Delord, J.; Besset, T.; Maes, B. U. W.; Schnürch, M. A comprehensive overview of directing groups applied in metalcatalysed C-H functionalisation chemistry Chem. Soc. Rev. 2018, $47,6603-6743$.

(15) (a) Nilsson, G. N.; Kerr, W. J. The development and use of novel iridium complexes as catalysts for ortho-directed hydrogen isotope exchange reactions J. Chem. Soc., Perkin Trans. 2 2010, 53, 662-667. (b) Brown, J. A.; Cochrane, A. R.; Irvine, S.; Kerr, W. J.; Mondal, B.; Parkinson, J. A.; Paterson, L. C.; Reid, M.; Tuttle, T.; Andersson, S.; Nilsson, G. N. The Synthesis of Highly Active Iridium(I) Complexes and their Application in Catalytic Hydrogen Isotope Exchange Adv. Synth. Catal. 2014, 356, 3551-3562. (c) Ma, S.; Villa, G.; Thuy-Boun, P. S.; Homs, A.; Yu, J.-Q. Palladium-catalyzed ortho-selective $\mathrm{C}-\mathrm{H}$ deuteration of arenes: evidence for superior reactivity of weakly coordinated palladacycles Angew. Chem., Int. Ed. 2014, 53, 734-737. (d) Giles, R.; Ahn, G.; Jung, K. W. H-D exchange in deuterated trifluoroacetic acid via ligand-directed NHC-palladium catalysis: a powerful method for deuteration of aromatic ketones, amides, and amino acids Tetrahedron Lett. 2015, 56, 6231-6235. (e) Kerr, W. J.; Lindsay, D. M.; Reid, M.; Atzrodt, J.; Derdau, V.; Rojahn, P.; Weck, R. Iridium-catalysed ortho-H/D and $\mathrm{H} / \mathrm{T}$ exchange under basic conditions: $\mathrm{C}-\mathrm{H}$ activation of unprotected tetrazoles Chem. Commun. 2016, 52, 6669-6672. (f) Valero, M.; Kruissink, T.; Blass, J.; Weck, R.; Güssregen, S.; Plowright, A. T.; Derdau, V. C-H Functionalization-Prediction of Selectivity in Iridium(I)-Catalyzed Hydrogen Isotope Exchange Competition Reactions Angew. Chem., Int. Ed. 2020, 59, 5626-5631. (g) Hu, G.-Q.; Li, E.-C.; Zhang, H.-H.; Huang, W. Ag(i)-Mediated hydrogen isotope exchange of mono-fluorinated (hetero)arenes Org. Biomol. Chem. 2020, 18, 6627-6633. (h) Kerr, W. J.; Knox, G. J.; Paterson, L. C. Recent advances in iridium(I) catalysis towards directed hydrogen isotope exchange J. Labelled Compd. Radiopharm. 2020, 63, 281-295.

(16) (a) Bag, S.; Petzold, M.; Sur, A.; Bhowmick, S.; Werz, D. B.; Maiti, D. Palladium-Catalyzed Selective meta-C-H Deuteration of Arenes: Reaction Design and Applications Chem. Eur. J. 2019, 25, 9433-9437. (b) Xu, H.; Liu, M.; Li, L.-J.; Cao, Y.-F.; Yu, J.-Q.; Dai, H.-X. Palladium-Catalyzed Remote meta-C-H Bond Deuteration of Arenes Using a Pyridine Template Org. Lett. 2019, 21, 4887-4891.

(17) (a) Burhop, A.; Weck, R.; Atzrodt, J.; Derdau, V. HydrogenIsotope Exchange (HIE) Reactions of Secondary and Tertiary Sulfonamides and Sulfonylureas with Iridium(I) Catalysts Eur. J. Org. Chem. 2017, 2017, 1418-1424. (b) Jess, K.; Derdau, V.; Weck, R.; Atzrodt, J.; Freytag, M.; Jones, P. G.; Tamm, M. Hydrogen Isotope Exchange with Iridium(I) Complexes Supported by PhosphineImidazolin-2-imine P,N Ligands Adv. Synth. Catal. 2017, 359, 629638. (c) Valero, M.; Becker, D.; Jess, K.; Weck, R.; Atzrodt, J.; Bannenberg, T.; Derdau, V.; Tamm, M. Directed Iridium-Catalyzed Hydrogen Isotope Exchange Reactions of Phenylacetic Acid Esters and Amides Chem. Eur. J. 2019, 25, 6517-6522. (d) Müller, V.; 
Weck, R.; Derdau, V.; Ackermann, L. Ruthenium(II)-Catalyzed Hydrogen Isotope Exchange of Pharmaceutical Drugs by $\mathrm{C}-\mathrm{H}$ Deuteration and C-H Tritiation ChemCatChem 2020, 12, 100-104. (e) Valero, M.; Bouzouita, D.; Palazzolo, A.; Atzrodt, J.; Dugave, C.; Tricard, S.; Feuillastre, S.; Pieters, G.; Chaudret, B.; Derdau, V. NHCStabilized Iridium Nanoparticles as Catalysts in Hydrogen Isotope Exchange Reactions of Anilines Angew. Chem., Int. Ed. 2020, 59, 3517-3522. (f) Daniel-Bertrand, M.; Garcia-Argote, S.; Palazzolo, A.; Mustieles Marin, I.; Fazzini, P.-F.; Tricard, S.; Chaudret, B.; Derdau, V.; Feuillastre, S.; Pieters, G. Multiple Site Hydrogen Isotope Labelling of Pharmaceuticals Angew. Chem., Int. Ed. 2020, 59, 21114-21120.

(18) (a) Kuhl, N.; Hopkinson, M. N.; Wencel-Delord, J.; Glorius, F. Beyond directing groups: transition-metal-catalyzed $\mathrm{C}-\mathrm{H}$ activation of simple arenes Angew. Chem., Int. Ed. 2012, 51, 1023610254. (b) Hartwig, J. F.; Larsen, M. A. Undirected, Homogeneous $\mathrm{C}-\mathrm{H}$ Bond Functionalization: Challenges and Opportunities ACS Cent. Sci. 2016, 2, 281-292. (c) Wedi, P.; van Gemmeren, M. AreneLimited Nondirected C-H Activation of Arenes Angew. Chem., Int. Ed. 2018, 57, 13016-13027. (d) Mondal, A.; Wedi, P.; Gemmeren, M. The Non-directed Distal C $\left(\mathrm{sp}^{2}\right)-\mathrm{H}$ Functionalization of Arenes. In Remote $\mathrm{C}-\mathrm{H}$ Bond Functionalizations; Maiti, D., Guin, S., Eds.; Wiley, 2021; pp 191-219.

(19) (a) Kański, R.; Kańska, M. Deuteriation of hydroxybenzoic acids in the presence of homogeneous platinum catalyst $J$. Radioanal. 2003, 257, 385-390. (b) Hanson, S. K.; Heinekey, D. M.; Goldberg, K. I. C-H Bond Activation by Rhodium(I) Phenoxide and Acetate Complexes: Mechanism of $\mathrm{H}-\mathrm{D}$ Exchange between Arenes and Water Organometallics 2008, 27, 1454-1463. (c) Hickman, A. J.; Villalobos, J. M.; Sanford, M. S. Quantitative Assay for the Direct Comparison of Platinum Catalysts in Benzene H/D Exchange Organometallics 2009, 28, 5316-5322. (d) Emmert, M. H.; Gary, J. B.; Villalobos, J. M.; Sanford, M. S. Platinum and palladium complexes containing cationic ligands as catalysts for arene H/D exchange and oxidation Angew. Chem., Int. Ed. 2010, 49, 58845886. (e) Rhinehart, J. L.; Manbeck, K. A.; Buzak, S. K.; Lippa, G. M.; Brennessel, W. W.; Goldberg, K. I.; Jones, W. D. Catalytic Arene H/D Exchange with Novel Rhodium and Iridium Complexes Organometallics 2012, 31, 1943-1952. (f) Iluc, V. M.; Fedorov, A.; Grubbs, R. H. H/D Exchange Processes Catalyzed by an IridiumPincer Complex Organometallics 2012, 31, 39-41. (g) Ibañez, S.; Poyatos, M.; Peris, E. Mono and dimetallic pyrene-imidazolylidene complexes of iridium(iii) for the deuteration of organic substrates and the C-C coupling of alcohols Dalton. Trans. 2016, 45, 1415414159. (h) Li, E.-C.; Hu, G.-Q.; Zhu, Y.-X.; Zhang, H.-H.; Shen, K.; Hang, X.-C.; Zhang, C.; Huang, W. $\mathrm{Ag}_{2} \mathrm{CO}_{3}$-Catalyzed H/D Exchange of FiveMembered Heteroarenes at Ambient Temperature Org. Lett. 2019, 21, 6745-6749. (i) Lassalle, S.; Jabbour, R.; Schiltz, P.; Berruyer, P.; Todorova, T. K.; Veyre, L.; Gajan, D.; Lesage, A.; Thieuleux, C.; Camp, C. Metal-Metal Synergy in Well-Defined Surface Tantalum-Iridium Heterobimetallic Catalysts for H/D Exchange Reactions J. Am. Chem. Soc. 2019, 141, 19321-19335. (j) Smith, J. D.; Durrant, G.; Ess, D. H.; Gelfand, B. S.; Piers, W. E. H/D exchange under mild conditions in arenes and unactivated alkanes with C6D6 and D20 using rigid, electron-rich iridium PCP pincer complexes Chem. Sci. 2020, 11, 10705-10717. (k) Martin, J.; Eyselein, J.; Grams, S.; Harder, S. Hydrogen Isotope Exchange with Superbulky Alkaline Earth Metal Amide Catalysts ACS Catal. 2020, 10, 7792-7799. (l) Dong, B.; Cong, X.; Hao, N. Silver-catalyzed regioselective deuteration of (hetero)arenes and $\alpha$-deuteration of 2-alkyl azaarenes RSC Adv. 2020, 10, 25475-25479. (m) Tlahuext-Aca, A.; Hartwig, J. F. Site-Selective Silver-Catalyzed C-H Bond Deuteration of Five-Membered Aromatic Heterocycles and Pharmaceuticals ACS Catal. 2021, 11, 1119-1127.

(20) (a) Yu, R. P.; Hesk, D.; Rivera, N.; Pelczer, I.; Chirik, P. J. Ironcatalysed tritiation of pharmaceuticals Nature 2016, 529, 195199. (b) Yang, H.; Zarate, C.; Palmer, W. N.; Rivera, N.; Hesk, D.; Chirik, P. J. Site-Selective Nickel-Catalyzed Hydrogen Isotope
Exchange in $\mathrm{N}$-Heterocycles and Its Application to the Tritiation of Pharmaceuticals ACS Catal. 2018, 8, 10210-10218. (c) Zarate, C.; Yang, H.; Bezdek, M. J.; Hesk, D.; Chirik, P. J. Ni(I)-X Complexes Bearing a Bulky $\alpha$-Diimine Ligand: Synthesis, Structure, and Superior Catalytic Performance in the Hydrogen Isotope Exchange in Pharmaceuticals J. Am. Chem. Soc. 2019, 141, 5034-5044. (d) Corpas, J.; Viereck, P.; Chirik, P. J. C( $\left(\mathrm{sp}^{2}\right)-\mathrm{H}$ Activation with Pyridine Dicarbene Iron Dialkyl Complexes: Hydrogen Isotope Exchange of Arenes Using Benzene- $\mathrm{d} 6$ as a Deuterium Source ACS Catal. 2020, 10, 8640-8647. (e) Garhwal, S.; Kaushansky, A.; Fridman, N.; Shimon, L. J. W.; Ruiter, G. de. Facile H/D Exchange at (Hetero)Aromatic Hydrocarbons Catalyzed by a Stable TransDihydride N-Heterocyclic Carbene (NHC) Iron Complex J. Am. Chem. Soc. 2020, 142, 17131-17139. (f) Yang, H.; Hesk, D. Base metal-catalyzed hydrogen isotope exchange J. Labelled Compd. Radiopharm. 2020, 63, 296-307.

(21) (a) Chen, H.; Wedi, P.; Meyer, T.; Tavakoli, G.; van Gemmeren, M. Dual Ligand-Enabled Nondirected C-H Olefination of Arenes Angew. Chem., Int. Ed. 2018, 57, 2497-2501. (b) Chen, H.; Mondal, A.; Wedi, P.; van Gemmeren, M. Dual Ligand-Enabled Nondirected C-H Cyanation of Arenes ACS Catal. 2019, 9, 19791984. (c) Mondal, A.; Chen, H.; Flämig, L.; Wedi, P.; van Gemmeren, M. Sterically Controlled Late-Stage C-H Alkynylation of Arenes $J$. Am. Chem. Soc. 2019, 141, 18662-18667. (d) Chen, H.; Farizyan, M.; Ghiringhelli, F.; van Gemmeren, M. Sterically Controlled C-H Olefination of Heteroarenes Angew. Chem., Int. Ed. 2020, 59, 12213-12220. (e) Mondal, A.; van Gemmeren, M. CatalystControlled Regiodivergent $\mathrm{C}-\mathrm{H}$ Alkynylation of Thiophenes* Angew. Chem., Int. Ed. 2021, 60, 742-746. (f) Santiago, C.; Chen, H.; Mondal, A.; van Gemmeren, M. Dual Ligand-Enabled Late-Stage Fujiwara-Moritani Reactions Synlett 2021. DOI: 10.1055/s-00401706014

(22) For selected examples of arene-limited non-directed $\mathrm{C}-\mathrm{H}$ activations with palladium catalysts, see: (a) Wang, P.; Verma, P.; Xia, G.; Shi, J.; Qiao, J. X.; Tao, S.; Cheng, P. T. W.; Poss, M. A.; Farmer, M. E.; Yeung, K.-S.; Yu, J.-Q. Ligand-accelerated non-directed C-H functionalization of arenes Nature 2017, 551, 489-493. (b) Naksomboon, K.; Valderas, C.; Gómez-Martínez, M.; Álvarez-Casao, Y.; Fernández-Ibáñez, M. Á. S,O-Ligand-Promoted PalladiumCatalyzed C-H Functionalization Reactions of Nondirected Arenes ACS Catal. 2017, 7, 6342-6346. (c) Naksomboon, K.; Poater, J.; Bickelhaupt, F. M.; Fernández-Ibáñez, M. Á. para-Selective C-H Olefination of Aniline Derivatives via Pd/S,O-Ligand Catalysis J. Am. Chem. Soc. 2019, 141, 6719-6725. (d) Da Zhao; Xu, P.; Ritter, T. Palladium-Catalyzed Late-Stage Direct Arene Cyanation Chem 2019, 5, 97-107. (e) Liu, L.-Y.; Yeung, K.-S.; Yu, J.-Q. LigandPromoted Non-Directed C-H Cyanation of Arenes Chem. Eur. J. 2019, 25, 2199-2202. (f) Liu, L.-Y.; Qiao, J. X.; Yeung, K.-S.; Ewing, W. R.; Yu, J.-Q. meta-Selective C-H Arylation of Fluoroarenes and Simple Arenes Angew. Chem., Int. Ed. 2020, 59, 13831-13835. (g) Dhankhar, J.; González-Fernández, E.; Dong, C.-C.; Mukhopadhyay, T. K.; Linden, A.; Čorić, I. Spatial Anion Control on Palladium for Mild C-H Arylation of Arenes J. Am. Chem. Soc. 2020, 142, 19040 19046. (h) Yin, B.; Fu, M.; Wang, L.; Liu, J.; Zhu, Q. Dual ligandpromoted palladium-catalyzed nondirected $\mathrm{C}-\mathrm{H}$ alkenylation of aryl ethers Chem. Commun. 2020, 56, 3293-3296.

(23) Wedi, P.; Farizyan, M.; Bergander, K.; Mück-Lichtenfeld, C.; van Gemmeren, M. Mechanism of the Arene-Limited Nondirected $\mathrm{C}-\mathrm{H}$ Activation of Arenes with Palladium. Angew. Chem., Int. Ed. 2021, 60, 15641-15649.

(24) The initial optimization studies were conducted using the reverse de-deuteration with deuterated HFIP-benzoate [D]1 as model substrate, see the SI for details. Uttry, A.; Mal, S.; van Gemmeren, M. Late-Stage $\beta-\mathrm{C}\left(\mathrm{sp}^{3}\right)-\mathrm{H}$ Deuteration of Carboxylic Acids J. Am. Chem. Soc. 2021, 143, 10895-10901. 


- No need of $\mathrm{DG} \quad \cdot$ Excellent functional group tolerance
- Novel ligand class
-36 examples

